\title{
Complete genome sequence of new unique recombinant HIV type 1 isolated from a child born to an HIV-infected mother
}

\author{
S Sasinovich", V Eremin, E Gasich, M Thomson
}

From International Symposium HIV and Emerging Infectious Diseases 2014

Marseille, France. 21-23 May 2014

\section{Introduction}

In our previously studies we detect a HIV recombinant form with BgagApolAenv by isolate named Mos. This virus differs from CRF02_AB with AgagBpolBenv. For more detailed studying of isolate Mos genome we carried out complete genome sequencing. (Figure 1).

\section{Materials and methods}

HIV-1 RNA was extracted from plasma, reverse transcribed, and amplified using sets of primers designed to span the complete genome of HIV-1. Contig assembled in SeqMan ${ }^{\circledR}$, DNAStar. Recombination analysis was performed using REGA HIV Subtyping Tool. Phylogenetic analysis was made in MEGA4 software with Kimura-2parametres.

\section{Results}

Analysis of complete genome shows that recombinant Mos is a new HIV-1 URF with gag/pol mosaic structure composed of parental subtypes $\mathrm{A}$ and $\mathrm{B}$ and rest genome composed of subtype A. Phylogenetical analysis had shown that HIV-1 subtype A ancestor is AY500393 Russia, subtype B - DQ207943 Georgia.

\section{Conclusions}

This study confirms the presence of a unique recombinant HIV-1 strain, emerging as a result of recombination between HIV-1 strains from Russia and Georgia.

Published: 23 May 2014

doi:10.1186/1471-2334-14-S2-P62

Cite this article as: Sasinovich et al:: Complete genome sequence of new unique recombinant HIV type 1 isolated from a child born to an HIV-infected mother. BMC Infectious Diseases 2014 14(Suppl 2):P62.

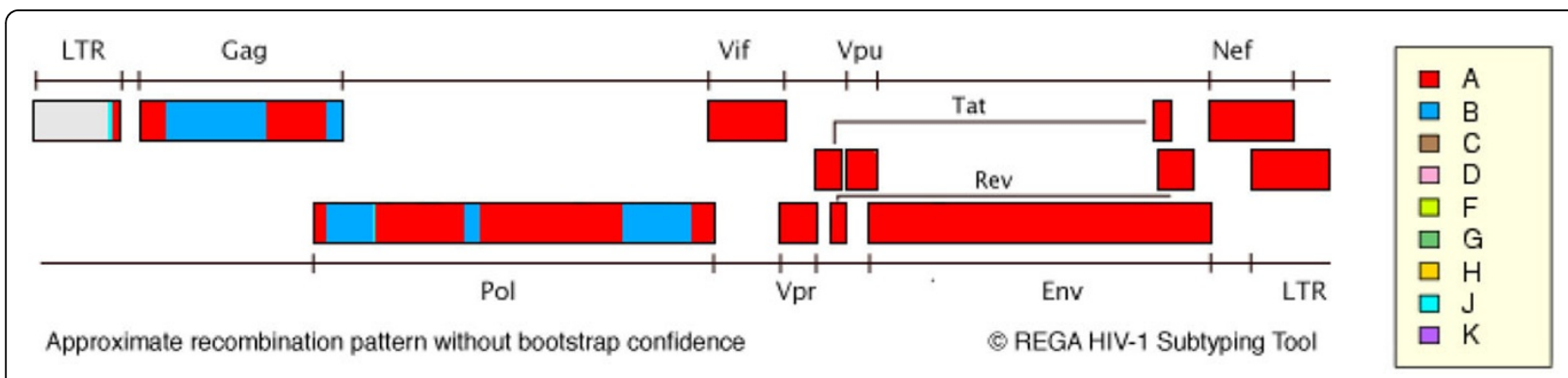

Figure 1

RRPC for Epidemiology and Microbiology, Minsk, Belorussia

(c) 2014 Sasinovich et al; licensee BioMed Central Ltd. This is an Open Access article distributed under the terms of the Creative Commons Attribution License (http://creativecommons.org/licenses/by/4.0), which permits unrestricted use, distribution, and reproduction in any medium, provided the original work is properly cited. The Creative Commons Public Domain Dedication waiver 